\title{
Factors influencing the communication of emotional intent by facial expressions
}

RICHARD M. DRAG AND MARVIN E, SHAW

UNIVERSITY OF FLORIDA

Forty-eight Ss attempted to communicate 10 emotions to four judges by means of facial expressions. Results agreed with those reported by Thompson \& Meltzer (1964) in showing that happiness was easiest and contempt most difficult to communicate, and that the Woodworth-Schlosberg scale consisted of five categories and was not circular. Also, females were found to be more effective than males in communicating happiness, love, fear, and anger. A measure of situational anxiety (the $A A C L$ ) failed to show the expected negative relationahip to accuracy of communication.

The communication of emotion is an integral factor in interpersonal behavior. It involves expression of emotion by one person and the interpretation of the expression by another. Curlously, most of the research on this important problem has been concerned with the perception of emotions (Bruner \& Tagiuri, 1954; Allport, 1961). However, persons not only communicate the emotions they are experiencing, but they also deliberately try to convince others that they are experiencing emotions they do not feel. The significance of this for effective social interaction has been elaborated by Goffman (1959), Thompson \& Meltzer (1964), Abrahamson (1966), and others.

There seems to be only one experimental study concerning the success with which persons can communicate emotional intent to others. Thompson \& Meltzer (1964) asked Ss to portray 10 emotions before four judges who attempted to identify the emotion. Sixtythree percent of all expressions were correctly identified, with happiness most ( $76 \%$ ) and contempt least ( $38 \%)$ frequently identified. This study raised several interesting questions concerning differences among emotions and individuals. Therefore the present experiment was designed to determine whether (a) the ThompsonMeltzer results concerning enactment ability could be replicated, (b) there are significant sex differences in enactment ability, (c) anxiety and enactment ability are correlated, and (d) Ss' perceptions of difficulty of portraying specific emotions are correlated with their success in expressing these emotions.

Method

Forty-eight college students served as Ss (expressors) in this experiment, 24 males and 24 females. All were volunteers who recelved no compensation for their service. Four judges, two male and two female college students, assisted in the study. All judges were naive with respect to judging emotional expressions. A 10-dollar bonus was offered for the judge who made the highest number of correct judgments. Each $S$ was seated behind a cardboard screen so that only his face and neck were exposed to the judges. He then attempted to portray ten emotions: happiness, love, fear, determination, bewilderment, surprise, anger, suffering, disgust, and contempt. Each emotion was attempted three times. The first five trials were practice trials and the last five were not scored to minimize the use of elimination by the judges. Thus each expressor attempted two critical enactments of each emotion, and four judges attempted to identify each enactment. The expressor's enactment score was the number of expressions correctly identified (range 0 to 8 ).

After the 30 enactment trials had been completed, each $\mathrm{S}$ was asked to rank order the emotions in terms of ease of enactment. He was then asked to respond to the Affect Adjective Check List (AACL). The AACL is a 61-item check list designed by Zuckerman (1960) to measure anxiety level over relatively brief periods of time. According to Zuckerman, the time set of the AACL can be changed by a simple adjustment of the instructions. In the present study, each $S$ was asked to check the words which describe "how you felt during the experiment."

Resulis

Table 1 gives the frequency of correct identification of each emotion and the means and variances of the enactment scores. Since the means and variances were correlated, scores were transformed by means of the square root transformation. Analysis of variance of the

Tahle 1.

Accuracy of Judgments of Expressors' Emotional Enactments

\begin{tabular}{|c|c|c|c|c|c|c|}
\hline \multirow{3}{*}{$\begin{array}{l}\text { Emotion \# } \\
\text { Enacted iu }\end{array}$} & \multicolumn{3}{|c|}{ Male Expressors } & \multicolumn{3}{|c|}{ Female Expressors } \\
\hline & \multirow{2}{*}{$\begin{array}{l}\text { \#Correct } \\
\text { judgments }\end{array}$} & \multicolumn{2}{|c|}{ Enactment Scores } & \multirow{2}{*}{$\begin{array}{l}\text { \#Correct } \\
\text { judgments }\end{array}$} & \multicolumn{2}{|c|}{ Enactment Scores } \\
\hline & & Mean & Variance & & Mean & Variance \\
\hline . & 119 & 4.96 & 7.5 & 152 & 6.33 & 4.72 \\
\hline & 13 & 5 & & & & 3.90 \\
\hline 年 & 10 & 4.29 & 6 & 13 & 5.71 & 4.22 \\
\hline-0 & 96 & 4.00 & 6.6 & 13 & 5.58 & 4.07 \\
\hline suffering & 85 & 3.54 & 5.4 & 10 & 4.29 & 6.55 \\
\hline Disgust & 87 & 3.63 & 3.8 & 102 & 4.25 & 4.20 \\
\hline Bewilderment & ent 86 & 3.58 & & 94 & 3.92 & 4.54 \\
\hline Anger & 68 & 2.83 & & 94 & 3.92 & 5 \\
\hline Det & ion 74 & & & 5 & & \\
\hline Contempt & 57 & 2.38 & 2.25 & 71 & 2.96 & 2.48 \\
\hline
\end{tabular}

- Maximum possible correct for each emotion $=192$. Emotions are listed in order of number correct for male and female expressors combined. 
transformed scores revealed significant differences attributable to Emotions ( $F=12.04, d f=9 / 414, p<.001$ ) and $\operatorname{Sex}(F=5.35, d f=1 / 46, p<.05)$. Overall, happiness was correctly identified most frequently (70\%) and contempt least frequently $(33 \%)$. This finding held for men, but not for women who were least effective in expressing determination. In general, women were more effective than men (56\% vs. $47 \%$ ); however, analysis of individual means revealed that this effect was limited to happiness, fear, love, and anger. Men were not significantly better than women for any emotion.

Scores on the AACL were correlated with enactment scores for each emotion taken separately and with overall enactment scores. Significant correlations were found for men between AACL scores and love (-.48) and and for women between AACL scores and surprise (.50). This is about the number expected by chance out of a set of 20 correlations. Overall correlations likewise falled to achieve significance $(-.23$ for men and .12 for women).

Thirty-nine of the 48 expressors followed instructions in ranking emotions in order of ease of enactment. Of these, 10 correlated significantly with rankings of enactment scores. The average correlation for all Ss was .37.

Finally, our results agree with Thompson and Meltzer in that the Woodworth-Schlosberg scale was found to have five steps, with disgust and contempt falling in the same category. (Bewilderment constituted a sixth step, but this emotion was not among those considered by Woodworth and Schlosberg.) There was no evidence of circularity.

Discussion

The results of this experiment agree with those reported by Thompson \& Meltzer (1964) in that (a) happiness was easiest and contempt most difficult to communicate, and (b) the Woodworth-Schlosberg scale consisted of five steps and was not circular. On the other hand, Thompson and Meltzer reported approximately $63 \%$ overall accuracy as compared with $52 \%$ in the present study. Also, the order of difficulty in communicating the various emotions found in the two studies correlated only .59; significant, but unimpressive. Finally, our results indicate that sex plays a greater role in effective communication than had been suggested by earlier findings.

How can we account for differences among emotions and individuals in ease of communication of emotions? At first thought, it appears that personality differences might be the answer. However, Thompson and Meltzer failed to find any correlation between enactment scores and 18 California Personality Inventory scores, and the present experiment failed to find a reliable relationship between enactment scores and a measure of situational anxiety. It is possible of course that the wrong traits have been considered or that the measuring instruments are inadequate, but it is more likely that the source of such differences lies in social forces. Social norms are such that a person is rewarded for the expression of happiness, love, and other "positive" emotions, but is punished for expressing contempt, anger, and similar "negative" emotions. Furthermore, different individuals, because of their position in the social group, may be reinforced differentially with respect to emotional expression. Consequently, ease of communication of emotional intent may be simply a function of the amount of practice the person has had in attempting to communicate the particular emotion. This interpretation is consistent with the sex differences observed in the present study. Expressions of happiness, love, fear, and anger are more characteristic of the female than of the male role, whereas expressions of other emotions (with the possible exception of determination) are probably not related to sex roles.

\section{References}

Abrahamson, M. Interpersonal accommodation. Princeton, N. J.: Van Nostrand, 1966.

Allport, G. W. Pattern and growth in personality. New York: Holt, Rinehart, and Winston, 1961. Ch. 20.

Bruner, J., \& Tagiuri, R. The perception of people. In G. Lindzey (Ed.), Handbook of social psychology. Vol. 2. Cambridge: Addison-Wesley, 1954. Pp. 634-654.

Gofman, E. The presentation of self in everyday life. Garden City N. Y.: Doubleday, 1959.

Thompson, D. F., \& Meltzer, L. Communication of emotional intent by facial expression. J. abnorm. soc. Psychol., 1964, 68, 129-135.

Zuckerman, M. The development of an Affect Adjective Check List for the measurement of anxiety. J. consult. Psychol., 1960, 24, 457-462. 